\title{
Prevalence and Predictors of Depression among Adolescents in Ido Ekiti, South West Nigeria
}

\author{
K. O. Oderinde ${ }^{1}$, M. U. Dada ${ }^{2}$, O. C. Ogun ${ }^{3}$, N. S. Awunor ${ }^{4}$, B. M. Kundi', \\ H. K. Ahmed ${ }^{6}$, A. B. Tsuung7, S. T. Tanko8, A. A. Yusuff ${ }^{8}$ \\ ${ }^{1}$ Department of Psychiatry, Yobe State University Teaching Hospital, Damaturu, Nigeria \\ ${ }^{2}$ Department of Psychiatry, Ekiti State University Teaching Hospital, Ado Ekiti, Nigeria \\ ${ }^{3}$ Child and Adolescent Psychiatry Department, Federal Neuropsychiatric Hospital, Lagos, Nigeria \\ ${ }^{4}$ Department of Community Medicine, College of Health Sciences, Delta State University, Abraka, Nigeria \\ ${ }^{5}$ Department of Psychiatry, Yobe State Specialist Hospital, Damaturu, Nigeria \\ ${ }^{6}$ Department of Mental Health, Federal Neuropsychiatric Hospital, Maiduguri, Nigeria \\ ${ }^{7}$ Department of Family Medicine, Yobe State University Teaching Hospital, Damaturu, Nigeria \\ ${ }^{8}$ Department of Family Medicine, Aminu Kano Teaching Hospital, Kano, Nigeria \\ Email: * psymedrecoverycentre@gmail.com
}

How to cite this paper: Oderinde, K.O., Dada, M.U., Ogun, O.C., Awunor, N.S., Kundi, B.M., Ahmed, H.K., Tsuung, A.B., Tanko, S.T. and Yusuff, A.A. (2018) Prevalence and Predictors of Depression among Adolescents in Ido Ekiti, South West Nigeria. International Journal of Clinical Medicine, 9, 187-202. https://doi.org/10.4236/ijcm.2018.93017

Received: February 2, 2018

Accepted: March 23, 2018

Published: March 26, 2018

Copyright (๑) 2018 by authors and Scientific Research Publishing Inc. This work is licensed under the Creative Commons Attribution International License (CC BY 4.0).

http://creativecommons.org/licenses/by/4.0/ (c) (i) Open Access

\begin{abstract}
Background: Depression among adolescents has been recognized as a public health problem all over the world. In Nigeria, as in most developing countries, there is a need for more research on the epidemiology of adolescent depression as this will guide prevention, diagnosis and treatment. Objectives: The study sought to determine the one month prevalence and predictors of depression among a sample of in-school adolescents in a rural region in South West Nigeria. Materials and Methods: This was a cross sectional descriptive survey among 540 secondary school students randomly selected from the six secondary schools in the study area using a Socio demographic Questionnaire and the Patient Health Questionnaire modified for Adolescents. Subsequently, a proportion of them were interviewed with the Kiddies Schedule for Affective Disorders and Schizophrenia. Results: Data were analyzed using the SPSS version 17. Respondents were aged 10 - 19 years (mean age was $14.07 \pm 1.84$ ). The one month prevalence of depression among the study population was $16.3 \%$ (using weighting method). Logistic regression analysis showed that death of a mother ( $\mathrm{OR}=11.786,95 \% \mathrm{CI}, 1.990-23.184)$, being from a polygamous family ( $\mathrm{OR}=5.781,95 \% \mathrm{CI}, 3.253$ - 24.371), low socioeconomic class $(\mathrm{OR}=6.222,95 \% \mathrm{CI}, 4.705-23.379)$, having a single parent $(\mathrm{OR}=2.236,95 \%$ $\mathrm{CI}, 0.869$ - 11.786), having witnessed frequent violence ( $\mathrm{OR}=12.411,95 \% \mathrm{CI}$, $0.516-29.851)$ and positive history of sexual abuse $(\mathrm{OR}=0.203,95 \% \mathrm{CI}$,
\end{abstract}


$0.003-0.529)$ were significantly and independently associated with depression in this sample of adolescents. Conclusion: The one month prevalence of adolescent depression within the study population is slightly higher than what has been reported in other parts of the world. Therefore, there is a need for government to design and implement policies which can help to prevent, detect early, and treat depression among youths especially in rural areas.

\section{Keywords}

Prevalence, Depression, Adolescents, Predictors

\section{Introduction}

Depressive disorder as defined by the World Health Organization (WHO) is a mental disorder characterized by an all-encompassing low mood, loss of interest and enjoyment and reduced energy leading to increased fatigability and diminished activity [1]. It is the most common form of emotional problem experienced during adolescence and may be accompanied by inappropriate guilt or regret, worthlessness, hopelessness, and confused thinking [2] [3]. Depression in adolescents is a highly prevalent condition that is often under recognized by families and physicians alike [4]. One of the factors that make depression so difficult to diagnose in adolescents is the common behaviour changes that are normally associated with the hormonal changes of the period [5]. The reported one month prevalence rates of depression among adolescents in developed countries range between $3 \%$ - $20 \%$ with lifetime prevalence rates estimated to range from $15 \%-35 \%$ by late adolescence [6].

In urban community settings of developing countries such as Kenya, Khasakhala et al. [7] reported $26.4 \%$ as the one month prevalence of depression among 1276 adolescents in Nairobi. In Nigeria, Omigbodun et al. [8] reported $12.6 \%$ as prevalence of probable depression among adolescents in rural South West Nigeria and found experiencing traumatic events as one of the predictors of depression especially when the event directly affected the youth as in sexual assault or physical abuse.

Nigeria has a relatively young population with $44 \%$ of the nation's population falling below the age of $19 \%$ and $55 \%$ of these live in rural area [9]. This study seeks to provide important information on the prevalence and predictors of depression among rural adolescents in this environment. It is hoped that a better understanding of adolescent depression in this environment will serve as a baseline for planning interventions for possible prevention, early detection and treatment.

\section{Materials and Methods}

This was a cross sectional descriptive survey conducted among secondary school students in Ido Ekiti, Ekiti State, Nigeria using a stratified proportional random 
sampling to select respondents from the six secondary schools in the town. The location of the study was in IdoEkiti in Ido/Osi Local Government Area of Ekiti State in the South Western geographical zone of Nigeria.

The total number of students in the six secondary schools in Ido-Ekiti was 1771 comprising 1104 junior secondary school students and 667 senior secondary school students. Subjects included in this study were selected from the school register using a table of random numbers. Those who were absent on the day of the study and those who were not within the age range 10 - 19 years were skipped and replaced by other students from the class register using the same table of random numbers.

The study was carried out in two stages. The first stage involved administration of the Socio demographic Questionnaire and Patient Health Questionnaire-9 modified for adolescents (PHQ-A). This was followed up on the same day with a semi-structured diagnostic interview using the depressive disorders module of Kiddies-Schedule for Affective disorders and Schizophrenia (Kiddies-SADS) to those participants with scores suggestive of depressive disorder on PHQ-A namely all those with PHQ-A scores $\geq 5$ which is the optimal cut off score for depressive disorders on PHQ-A validated in this environment [10]. Fifteen percent (15\%) of those with PHQ-A scores $<5$ were also randomly selected. This was in line with the two stage epidemiological study by Gureje et al. [11] to assess psychiatric disorders in a paediatric primary care clinic where $15 \%$ of those screened negative on Parents' version of Rutter scale were also subjected to the K-SADS. The randomization in this study was by writing YES or NO on papers which were rumpled and given to those who screened negative on PHQ-A and those who picked YES were interviewed with depressive disorder module of Kiddies-SADS in the second stage to correct for possible missed cases, thus improving the yield of identified cases.

Students were eligible for participation if they were between 10 and 19 years of age and had given assent and had oral/written consent from their parents/ guardians. Students were excluded if they were severely physically ill during the period of questionnaire administration, had a previous history of mental illness as ascertained by the Socio-Demographic Questionnaire.

The study protocol was approved by the Research and Ethical Committee of the Federal Teaching Hospital, Ido-Ekiti. Written permission was obtained from Ido/Osi Local Government Area Education Office and the principals of the participating schools. Participation was voluntary and informed consent was obtained from the parents of the respondents while the adolescents' assent was also obtained.

The sample size that was used for this study was computed based on the Cochrane formula for calculating sample size in cross sectional studies [12] while adjusting for a design effect using the prevalence rate of $12.1 \%$ of depressive disorder among adolescents in rural South Western Nigeria [13]. Adjusting for non response rate of $10 \%$, an estimated sample size of 540 was chosen to in- 
crease the statistical power of the study.

Data was collected using a semi structured questionnaire for socio demographic characteristics of respondents and a Patient Health Questionnaire (PHQ-9) modified for Adolescents (PHQ-A) and Kiddies-Schedule for Affective disorders and Schizophrenia (Kiddies-SADS).

The Patient Health Questionnaire (PHQ-9) modified for Adolescents (PHQ-A) is a nine item questionnaire which screens for depression. It is useful for assisting primary care clinicians in screening for depression as well as monitoring treatment. The PHQ-9 scores each of the nine DSM-IV criteria as "O" (not at all) to "3" (nearly every day). It has been validated for use in Nigeria by Adewuya et al. [10] who reported an internal consistency of 0.85 and optimal cut-off score for depressive disorder as 5 (sensitivity 0.897 , specificity 0.989 , positive predictive value 0.875 , negative predictive value 0.981 ). The PHQ-A was modified from PHQ-9 for use in adolescents where it also has acceptable psychometric properties [14] [15] [16].

In this study, a cut off of 5 was employed as cut off for depression as recommended by Adewuya et al [10]. This cut off has been used in South West, Nigeria to assess the prevalence and predictors of depression among school adolescents in a rural area in Oyo State [17].

The Kiddies-Schedule for Affective disorders and Schizophrenia (Kiddies-SADS) is a semi structured diagnostic interview designed to assess current and past episodes of psychopathology in children and adolescents according to Diagnostic and Statistical Manual of Mental Disorders third and fourth edition criteria (DSM-III and IV) [18]. However, in this study, only the current episode in the last one month was elicited using the depressive disorder module of Kiddies-SADS.

A pre-test was conducted in a non-participating secondary school (OraEkiti Community High School, OraEkiti) which is about 3 kilometers away from the study area. This aimed at ascertaining the duration of administration and acceptability of instruments used in the main study. Areas of difficulties that could be encountered during the main study were also identified.

This cross sectional survey was carried out between the month of December 2013 and January, 2014. The investigators ensured that a separate classroom was provided for the conduct of the interview with the students. Also, the different schools were asked to give convenient days and free periods for data collection based on the weekly programme of each school to minimize disruption in school activities. With the collaboration of the teachers, the selected students were moved to a separate classroom where instructions were given to them as to how the interview would be conducted in order to ensure confidentiality and an atmosphere devoid of intimidation.

The selected students were also advised to bring one of their parents/guardians to the school on the day of interview to corroborate the depressive symptoms. The students were educated about mental health and psychosocial consequences 
of depression at the end of the data collection process in each school. After the study interviews, the investigators went back to the different schools to identify students who were found to be depressed. The students who were found to be mildly depressed were referred to their school counsellors and those severely depressed to the mental health department of the Federal Teaching Hospital, Ido-Ekiti, Ekiti State.

The data obtained were coded where appropriate, entered and analyzed using the SPSS version 17. Data exploration was carried out using frequencies. Data was summarized using frequencies, percentages, means and standard deviation. The Chi square test was used to test for associations between categorical variables (socio demographic variables) and outcome variables (depression) while the binary logistic regression was used to determine the variables that were independently associated with depression. The level of significance was set at 0.05 , two tailed.

\section{Results}

\subsection{Socio Demographic Characteristics of Respondents}

The study population was made up of 276 (51.1\%) males and 264 (48.9\%) females giving a male: female ratio of 1.1:1. Their ages ranged from 10 to 19 years with a mean age of 14.07 years (SD \pm 1.84$)$. More than half of them (58.0\%) were in the age range of 13 - 15 years, about one fifth of them (19.6\%) were in the age range 10 - 12 years, and those in the age group 15 - 19 years were $22.4 \%$. Majority (81.7\%) were Christians and about one sixth of them (16.7\%) were Muslims. A little above half $(57.6 \%)$ were in public schools. About two thirds of them (62.4\%) were in the junior secondary school class (JSS1-JSS3).

Majority of the fathers of the respondents had at least secondary education (73.9\%) and were in the intermediate occupational class or artisans/drivers (74.5\%). Also, majority of the mothers of the respondents had at least secondary school education $(76.9 \%)$ and were in the intermediate occupational class or artisans/drivers group (75.6\%). Forty three percent of the respondents were from middle and high socio economic classes (See Table 1).

\subsection{Family Characteristics and Social Relationships of Respondents}

Majority of them (60.6\%) were from monogamous family setting while $39.4 \%$ were of polygamous family. Almost half of the respondents (47.2\%) lived with both parents. About one fifth of them (22.2\%) had lost their mother. About one quarter of them (24.4\%) had widowed parents, $11.3 \%$ had divorced parents while $58.5 \%$ reported that their biological parents were married.

Majority reported cordial relationships with their parents, siblings, teachers and school mates $(76.3 \%, 87.6 \%, 88.1 \%$ and $94.3 \%$ respectively) (See Table 2 ).

\subsection{Prevalence of Depression}

The prevalence of depression among the respondents was $16.3 \%$ using sampling 
Table 1. Socio demographic characteristics of respondents $\mathrm{N}=540$.

\begin{tabular}{|c|c|c|}
\hline Variables & Frequency (n) & Percent (\%) \\
\hline \multicolumn{3}{|l|}{ Age group (yrs) } \\
\hline $10-12$ & 106 & 19.6 \\
\hline $13-15$ & 313 & 58.0 \\
\hline $16-19$ & 121 & 22.4 \\
\hline \multicolumn{3}{|l|}{ Gender } \\
\hline Male & 276 & 51.1 \\
\hline Female & 264 & 48.9 \\
\hline \multicolumn{3}{|l|}{ Religion } \\
\hline Islam & 90 & 16.7 \\
\hline Christianity & 441 & 81.7 \\
\hline${ }^{\star}$ Others & 9 & 1.6 \\
\hline \multicolumn{3}{|l|}{ School type } \\
\hline Public schools & 311 & 57.6 \\
\hline Private schools & 229 & 42.4 \\
\hline \multicolumn{3}{|l|}{ Class groups } \\
\hline JSS Class & 337 & 62.4 \\
\hline SSS Class & 203 & 37.6 \\
\hline \multicolumn{3}{|l|}{ Father's Education } \\
\hline Tertiary & 255 & 47.2 \\
\hline Secondary & 144 & 26.7 \\
\hline Primary & 131 & 24.3 \\
\hline None & 10 & 1.9 \\
\hline \multicolumn{3}{|l|}{ Father's Occupation } \\
\hline Professionals & 49 & 9.1 \\
\hline Intermediate & 176 & 32.6 \\
\hline Artisans and Drivers & 226 & 41.9 \\
\hline Petty traders and Messengers & 89 & 16.5 \\
\hline \multicolumn{3}{|l|}{ Mother's Education } \\
\hline Tertiary & 211 & 39.1 \\
\hline Secondary & 204 & 37.8 \\
\hline Primary & 102 & 18.9 \\
\hline None & 23 & 4.3 \\
\hline \multicolumn{3}{|l|}{ Mother's Occupation } \\
\hline Professionals & 59 & 10.9 \\
\hline Intermediate & 209 & 38.7 \\
\hline Artisans and Drivers & 199 & 36.9 \\
\hline Petty traders and Messengers & 73 & 13.5 \\
\hline \multicolumn{3}{|l|}{ Social class } \\
\hline Upper class & 37 & 6.9 \\
\hline Middle class & 195 & 36.1 \\
\hline Lower class & 308 & 57.0 \\
\hline
\end{tabular}

*Others: traditional religion. 
Table 2. Family characteristics and social relationships of respondents.

\begin{tabular}{|c|c|c|}
\hline Variables & Frequency (\%) & Percent (n) \\
\hline \multicolumn{3}{|l|}{ Current living status } \\
\hline Both Parents & 255 & 47.2 \\
\hline Single parent & 135 & 25.0 \\
\hline${ }^{\star}$ Others & 150 & 27.8 \\
\hline \multicolumn{3}{|l|}{ Status of parent } \\
\hline Father dead & 41 & 7.6 \\
\hline Mother dead & 120 & 22.2 \\
\hline \multicolumn{3}{|l|}{ Parent's Marital Status } \\
\hline Never Married & 21 & 3.9 \\
\hline Married & 316 & 58.5 \\
\hline Divorced & 61 & 11.3 \\
\hline Widowed & 132 & 24.4 \\
\hline Both Parents dead & 10 & 1.9 \\
\hline \multicolumn{3}{|l|}{ Type of Family } \\
\hline Monogamous & 327 & 60.6 \\
\hline Polygamous & 213 & 39.4 \\
\hline \multicolumn{3}{|l|}{ Birth order } \\
\hline First (Eldest Child) & 148 & 27.4 \\
\hline Lastborn & 135 & 25.0 \\
\hline Only Child & 22 & 4.1 \\
\hline Others $\left(2^{\text {nd }}, 3^{\text {rd }}, 4^{\text {th }}\right.$ etc $)$ & 235 & 43.5 \\
\hline \multicolumn{3}{|l|}{ Relationship with Father } \\
\hline Not applicable (Dead or not around) & 38 & 7.0 \\
\hline Cordial & 412 & 76.3 \\
\hline Not Cordial & 90 & 16.7 \\
\hline \multicolumn{3}{|l|}{ Relationship with mother } \\
\hline Not applicable (Dead or not around) & 75 & 13.9 \\
\hline Cordial & 448 & 83.0 \\
\hline Not Cordial & 17 & 3.1 \\
\hline \multicolumn{3}{|l|}{ Relationship with siblings } \\
\hline Not applicable (No siblings) & 19 & 3.5 \\
\hline Cordial & 473 & 87.6 \\
\hline Not Cordial & 48 & 8.9 \\
\hline \multicolumn{3}{|l|}{ Relationship with Teachers } \\
\hline Cordial & 476 & 88.1 \\
\hline Not Cordial & 64 & 11.9 \\
\hline \multicolumn{3}{|l|}{ Relationship with School mates } \\
\hline Cordial & 509 & 94.3 \\
\hline Not Cordial & 29 & 5.4 \\
\hline No response & 2 & 0.4 \\
\hline
\end{tabular}

*Others: aunties, uncles, cousins. 
weights. Those in the age group greater than 15 years had a higher prevalence (23.1\%) than those in the age groups 13 - 15 years $(13.7 \%)$ and $10-12$ years (13.2\%). Female adolescents had a higher prevalence (19.9\%) than their male counterparts (12.9\%). Respondents in public schools had a higher prevalence (18.0\%) than those in private schools $(14.9 \%)$. Adolescents in the senior secondary class group (SSSI-SSS3) had higher prevalence of $18.1 \%$ than those in the junior secondary class group of $15.3 \%$ (See Table 3 ).

\subsection{Association between Depression and Socio Demographic Variables}

Older age was significantly associated with depression as respondents in the 15 19 years category $(23.1 \%)$ were found to be depressed when compared to those aged $13-15$ years $(13.7 \%)$ and $10-12$ years $(13.2 \%)\left(x^{2}=12.159, \mathrm{df}=2, \mathrm{p}=\right.$ $0.002)$. Gender was not significantly associated with depression as the proportion of males (12.9\%) who were found to be depressed were not significantly different from the proportion of females (19.9\%) who were found to be depressed. $\left(\mathrm{x}^{2}=0.035, \mathrm{df}=1, \mathrm{p}=0.852\right)$ (See Table 4).

Table 3. Prevalence of depression among respondents.

\begin{tabular}{|c|c|c|c|}
\hline \multirow{2}{*}{ Category } & \multirow{2}{*}{ Total, $\mathbf{n}$} & \multicolumn{2}{|c|}{ Prevalence $(95 \%$ CI $) \%$} \\
\hline & & Unweighted & Weighted \\
\hline Total & 182 & $33.7(29.8-37.8)$ & $16.3(14.6-18.2)$ \\
\hline \multicolumn{4}{|l|}{ Age group (yrs) } \\
\hline $10-12$ & 21 & $19.8(13.3-28.4)$ & $13.2(10.6-16.4)$ \\
\hline $13-15$ & 112 & $35.8(30.7-41.2)$ & $13.7(11.3-16.7)$ \\
\hline$>15$ & 49 & $40.5(32.2-49.4)$ & $23.1(19.6-27.1)$ \\
\hline \multicolumn{4}{|l|}{ Gender } \\
\hline Male & 92 & $33.3(28.0-39.1)$ & $12.9(10.8-15.3)$ \\
\hline Female & 90 & $34.1(28.6-40.0)$ & $19.9(17.3-22.8)$ \\
\hline \multicolumn{4}{|l|}{ School } \\
\hline Oganganmodun & 76 & $43.2(36.1-50.6)$ & $13.6(10.9-17.0)$ \\
\hline Ekitiparapo & 46 & $34.1(26.6-42.4)$ & $16.4(13.1-20.4)$ \\
\hline Liberty & 32 & $32.0(23.7-41.7)$ & $19.8(15.6-24.7)$ \\
\hline OkeOsanyintolu & 16 & $23.2(14.8-34.4)$ & $16.5(12.0-22.3)$ \\
\hline Christ Public. & 8 & $22.2(11.7-38.1)$ & $18.8(13.6-25.4)$ \\
\hline Christ-Led College & 4 & $16.7(6.7-35.9)$ & $14.6(8.9-23.0)$ \\
\hline \multicolumn{4}{|l|}{ School type } \\
\hline Public schools & 122 & $39.2(34.0-44.8)$ & $18.0(15.5-20.9)$ \\
\hline Private schools & 60 & $26.2(20.9-32.3)$ & $14.9(12.7-17.4)$ \\
\hline \multicolumn{4}{|l|}{ Class type } \\
\hline JSS Class & 102 & $30.3(25.6-35.4)$ & $15.3(13.2-17.6)$ \\
\hline SSS Class & 80 & $39.4(29.4-44.6)$ & $18.1(15.3-21.4)$ \\
\hline
\end{tabular}


Table 4. Association between depression and socio demographic characteristics of respondents $(\mathrm{N}=540)$.

\begin{tabular}{|c|c|c|c|c|c|}
\hline Variables & Depressed & Not Depressed & $\chi^{2}$ & df & $P$ value \\
\hline \multicolumn{6}{|l|}{ Age group (yrs) } \\
\hline $10-12$ & $21(19.8)$ & $85(80.2)$ & 12.259 & 2 & $0.002^{*}$ \\
\hline $13-15$ & $112(35.8)$ & $201(64.2)$ & & & \\
\hline $16-19$ & $49(40.5)$ & $72(59.5)$ & & & \\
\hline \multicolumn{6}{|l|}{ Gender } \\
\hline Male & $92(33.3)$ & $184(66.7)$ & 0.035 & 1 & 0.852 \\
\hline Female & $90(34.1)$ & $174(65.9)$ & & & \\
\hline \multicolumn{6}{|l|}{ Religion } \\
\hline Islam & $27(30.0)$ & $63(70.0)$ & 0.668 & 2 & 0.716 \\
\hline Christianity & $152(34.5)$ & $289(65.5)$ & & & \\
\hline${ }^{\star}$ Others & $3(33.3)$ & $6(66.7)$ & & & \\
\hline \multicolumn{6}{|l|}{ School type } \\
\hline Public schools & $122(39.2)$ & $189(60.8)$ & 10.017 & 1 & $0.002^{*}$ \\
\hline Private schools & $60(26.2)$ & $169(73.8)$ & & & \\
\hline \multicolumn{6}{|l|}{ Class groups } \\
\hline JSS Class & $102(30.3)$ & $235(69.7)$ & 4.738 & 1 & $<0.001^{*}$ \\
\hline SSS Class & $80(39.4)$ & $123(60.6)$ & & & \\
\hline \multicolumn{6}{|l|}{ Father's Education } \\
\hline Tertiary & $31(12.2)$ & $224(87.8)$ & 148.65 & 3 & $<0.001^{*}$ \\
\hline Secondary & $51(35.4)$ & $93(64.6)$ & & & \\
\hline Primary & $97(74.0)$ & $34(26.0)$ & & & \\
\hline None & $3(30.0)$ & $7(70.0)$ & & & \\
\hline \multicolumn{6}{|l|}{ Father's Occupation } \\
\hline Professionals & $2(4.1)$ & $47(95.9)$ & 97.576 & 3 & $<0.001^{*}$ \\
\hline Intermediate & $32(18.2)$ & $144(81.8)$ & & & \\
\hline Artisans and Drivers & $84(37.2)$ & $142(62.8)$ & & & \\
\hline Petty trader and Messengers & $64(71.9)$ & $25(28.1)$ & & & \\
\hline \multicolumn{6}{|l|}{ Mother's Education } \\
\hline Tertiary & $14(6.6)$ & $197(93.4)$ & 155.286 & 3 & $<0.001^{*}$ \\
\hline Secondary & $85(41.7)$ & $119(58.3)$ & & & \\
\hline Primary & $77(75.5)$ & $25(24.5)$ & & & \\
\hline None & $6(26.1)$ & $17(73.9)$ & & & \\
\hline \multicolumn{6}{|l|}{ Mothers Occupation } \\
\hline Professionals & $3(5.1)$ & $56(94.9)$ & 104.351 & 3 & $<0.001^{*}$ \\
\hline Intermediate & $49(23.4)$ & $160(76.6)$ & & & \\
\hline Artisans and Drivers & $71(35.7)$ & $128(64.3)$ & & & \\
\hline Petty trader and Messengers & $59(80.8)$ & $14(19.2)$ & & & \\
\hline \multicolumn{6}{|l|}{ Social class } \\
\hline Upper class & $8(4.0)$ & $29(96.0)$ & 138.786 & 2 & $<0.001^{*}$ \\
\hline Middle class & $63(32.3)$ & $132(67.7)$ & & & \\
\hline Lower class & $111(36.0)$ & $197(64.0)$ & & & \\
\hline
\end{tabular}

${ }^{*}$ Significant at $\mathrm{p}$ value $<0.05$. 
A higher proportion of subjects from senior secondary class (18.1\%) were found to be depressed when compared to those in the junior secondary class $(15.3 \%)$ and this was statistically significant $\left(x^{2}=4.738, d f=1, p \leq 0.001\right)$. Low socioeconomic class was also significantly associated with depression as a higher proportion of respondents in the low socioeconomic class (36.0\%) were found to be depressed when compared to those in the upper socioeconomic class $(4.0 \%)$. $\left(\mathrm{x}^{2}=195.688, \mathrm{df}=2, \mathrm{p}<0.001\right)($ See Table 4$)$.

\subsection{Factors Independently Associated with Depression}

The socio demographic variables that were significantly associated with depression on chi square analysis were entered into a logistic regression analysis equation. These were age, school type, class group, current living status, death of parent(s), type of family, birth order, social class, relationships with father, mother, siblings, and teachers. Others were academic performance, witness of neighbourhood violence and report of sexual/physical abuse (See Table 5). Independent variables with two categories or more had their first category taken as reference and assigned an odd ratio of 1 , while the effect of other categories was compared with this reference category.

Logistic regression analysis showed that lower social class was found to have a six fold increase in the risk of depression when compared to those in the upper class (OR $=6.222,95 \% \mathrm{CI}, 4.705$ - 23.379). Death of mother also increased the risk of depression by almost twelve fold and was found to be significantly and independently associated with depression ( $\mathrm{OR}=11.786,95 \% \mathrm{CI}, 1.990-23.184)$.

Being from a polygamous family setting increased the chance of being depressed by approximately six fold when compared to those from monogamous family (OR = 5.781, 95\% CI, 3.253 - 24.371). Having witnessed neighbourhood violence frequently also increased the risk of being a depressed by twelve fold when compared to those who never witnessed neighbourhood violence $(\mathrm{OR}=$ $12.411,95 \%$ CI, 0.516 - 29.851).

Negative history of sexual abuse was found to be significantly protective against depression as respondents who had negative history of sexual abuse were five times less likely to be depressed when compared to those who had positive history of sexual abuse (OR = 0.203, 95\% CI, 0.003 - 0.529) (See Table 5). Cordial relationship with mother was also found to be significantly protective against depression as respondents who had cordial relationship with their mothers were four times less likely to be depressed when compared to those who had no cordial relationship with their mothers $(\mathrm{OR}=0.252,95 \% \mathrm{CI} ; 0.000-0.358)$.

\section{Discussion}

The one month prevalence rate of depression of $16.3 \%$ obtained in this study is within the range of findings from previous studies from developing and developed countries [4] [13]. Omigbodun et al [13], in a cross sectional study among 484 adolescent students in two rural districts of South Western Nigeria using the 
Table 5. Logistic regression analysis for the variables independently associated with depression.

\begin{tabular}{|c|c|c|c|c|}
\hline \multicolumn{2}{|l|}{ Variables } & B & OR $(95 \% \mathrm{CI})$ & $P$ value \\
\hline \multirow[t]{3}{*}{ Age group (yrs) } & $10-12$ & & 1 & \\
\hline & $13-15$ & -0.941 & $0.390(0.065-2.353)$ & 0.305 \\
\hline & $>15$ & -0.800 & $0.449(0.007-29.538)$ & 0.708 \\
\hline \multirow[t]{2}{*}{ School type } & Public & & 1 & \\
\hline & Private & 0.135 & $1.145(0.212-6.192)$ & 0.875 \\
\hline \multirow[t]{2}{*}{ Class groups } & JSS Class & & 1 & \\
\hline & SSS Class & -0.610 & $0.543(0.032-9.357)$ & 0.674 \\
\hline \multirow[t]{3}{*}{ Social class } & Upper class & & 1 & \\
\hline & Middle class & 1.999 & $5.381(0.898-60.648)$ & 0.063 \\
\hline & Lower class & 4.131 & $6.222(4.705-23.379)$ & 0.002 \\
\hline \multirow[t]{3}{*}{ Current living status } & Both Parents & & 1 & \\
\hline & Single parent & 2.521 & $2.236(0.869-11.786)$ & 0.006 \\
\hline & ${ }^{\star}$ Others & 3.616 & $5.125(4.136-20.789)$ & 0.011 \\
\hline \multirow[t]{2}{*}{ Death of parent (Father) } & No & & 1 & \\
\hline & Yes & -1.781 & $0.168(0.009-3.055)$ & 0.228 \\
\hline \multirow[t]{2}{*}{ Death of parent (Mother) } & No & & 1 & \\
\hline & Yes & 4.770 & $11.786(1.990-23.184)$ & 0.022 \\
\hline \multirow[t]{2}{*}{ Type of Family } & Monogamy & & 1 & \\
\hline & Polygamy & 3.577 & $5.781(3.253-24.371)$ & $<0.001$ \\
\hline \multirow[t]{4}{*}{ Birth order } & First (Eldest Child) & & 1 & \\
\hline & Lastborn & -0.357 & $0.700(0.038-12.880)$ & 0.810 \\
\hline & Only Child & -5.908 & $0.003(0.000-24.314)$ & 0.203 \\
\hline & Others & 0.869 & $2.384(0.234-24.323)$ & 0.463 \\
\hline \multirow[t]{3}{*}{ Relationship with Father } & None & & 1 & \\
\hline & Cordial & 0.256 & $1.292(0.059-28.249)$ & 0.871 \\
\hline & Not Cordial & 3.760 & $4.293(0.936-19.680)$ & 0.054 \\
\hline \multirow[t]{3}{*}{ Relationship with mother } & None & & 1 & \\
\hline & Cordial & -5.016 & $0.252(0.000-0.358)$ & 0.014 \\
\hline & Not Cordial & 3.308 & $27.331(0.012-62.402)$ & 0.402 \\
\hline \multirow[t]{3}{*}{ Relationship with siblings } & None & & 1 & \\
\hline & Cordial & -0.684 & $0.504(0.001-21.309)$ & 0.824 \\
\hline & Not Cordial & 1.810 & $6.109(0.005-24.116)$ & 0.623 \\
\hline \multirow[t]{2}{*}{ Relationship with Teachers } & Cordial & & 1 & \\
\hline & Not Cordial & -2.093 & $0.123(0.006-2.519)$ & 0.174 \\
\hline \multirow[t]{2}{*}{ Self-rated academic performance } & Above Average & & 1 & \\
\hline & Average & 1.218 & $3.380(0.010-11.258)$ & 0.681 \\
\hline
\end{tabular}


Continued

\begin{tabular}{ccccc}
\hline & Below Average & 4.828 & $12.495(0.299-52.237)$ & 0.117 \\
Witnessed neighbourhood Violence & Never & & 1 & \\
& & & & \\
& Sometimes & 1.319 & $3.738(0.207-67.645)$ & 0.372 \\
& & & & \\
Report of Sexual abuse & Always & 2.519 & $12.411(0.516-29.851)$ & $\mathbf{0 . 0 1 8}$ \\
& Present & & 1 & \\
Report of Physical abuse & Absent & -3.261 & $0.203(0.003-0.529)$ & $\mathbf{0 . 0 1 5}$ \\
& Present & & 1 & 0.895 \\
Constant & Absent & 0.187 & $1.205(0.075-19.464)$ & 0.003 \\
\hline
\end{tabular}

*Others: aunties, uncles and cousins.

Diagnostic Interview Schedule for Children (DISC) reported a prevalence rate of probable depression to be $12.1 \%$. This prevalence is slightly lower than $16.3 \%$ obtained in this study. This variation in the finding from Omigbodun et al. [13] study compared to the current study may be due to varying methodological factors.

A more recent study by Fatiregun and Kumapayi in 2014 using Patient Health Questionnaire modified for adolescents reported the prevalence of depressive symptoms to be $21.2 \%$ among school adolescents in a rural district of Egbeda Local Government Area of Oyo State [17]. This prevalence rate is slightly higher than that obtained in this present study probably because only a screening instrument (the PHQ-A) was used in their study and no further diagnostic testing was done.

In other parts of developing world such as India, Nagendra et al. [19] using the Becks Depression Inventory reported a one month prevalence rate of depressive symptoms to be $57.7 \%$ in a sample of 3141 adolescent students within the age range $15-19$ years among public and private secondary school students. This prevalence is significantly higher than that observed in this study. This observation may be readily explained by variation in the instruments.

The prevalence of $16.3 \%$ in this study also correlates well with the findings of Saluja et al. [4] in the United States of America where a one month prevalence of depression among 863 young adolescents was reported as $18 \%$ using the Composite International Diagnostic Interview (CIDI). The slight difference in the rates between this study and the work of Saluja et al. [4] may be due to the different ages of the participants studied. Saluja et al. [4] studied adolescents of narrower age range of $11-15$ years while in this present study, those who participated were adolescents of broader age range of $10-19$ years. The reasons for the observed differences in prevalence rates of depression in this study compared to some of the cited studies may be due to methodological issues like sampling, 
study design and instruments used.

This study also found that the proportion of older adolescents in the age range 16 - 19 years who were found to be depressed was higher than the proportion of younger adolescents in the age range 10 - 12 years who were found to be depressed. Said and Hasan [20] also found similar results carried out among Turkish adolescents where they found that older adolescents reported depressive symptoms than younger adolescents. Possible reasons for this could be, societal expectations from older adolescents such as better academic performance, better conduct than the younger ones, hence they are more likely to experience more stressors than the younger adolescents [21]. Hormonally-linked heightened stress sensitivity in the older adolescents has been associated with higher prevalence estimates of depression among the older adolescents [22]. This is because hormonal changes produce behavioural and neural signs of depression by sensitizing the brain to the harmful effects of stress [22].

Socioeconomic class was also found to be significantly associated with depression in this study as students from lower socioeconomic status were six times more likely to be depressed than students from the upper socioeconomic status. This has been observed in other similar studies conducted in other parts of the world where they found that poverty and difficulties in meeting daily necessities may induce a child to compare himself with others and this situation increases child's tendency to depression [23] [24].

This present study also found that adolescents from polygamous families were almost six times more likely to be depressed than those from monogamous families and this was significantly and independently associated with depression on logistic regression. Previous studies have also linked polygamous family settings to adolescent depression [25] [26]. This might be due to parents in polygamous family settings being unable to fulfil the needs of their growing children as a result of more numbers in the family. Such needs would include food, clothing, education, love, care, emotional support, parental support and financial needs.

The finding of significant relationship between parental separation/divorce and depression in this study is in keeping with findings from other studies [27] [28]. These adolescents from separated/divorced families tend to be more depressed than their same aged peers from intact families. This could be, because such adolescents from divorced home tend to have less intimate relationship with their parents.

Death of a parent was also found to be significantly associated with adolescent depression in this study. Previous researchers have reported that adolescents who had experienced parental death were more likely to be depressed than those who had not [29] [30]. The reason for this observation is obvious, since such adolescents are often deprived of secure and loving relationships with their parents and these are protective factors that reduce the rate of emotional disorders among adolescents [31].

This study revealed that the one month prevalence of depression among ado- 
lescents in rural area appears slightly higher than that in urban area and is significantly and independently associated with lower socioeconomic class, polygamous family setting, having a single parent, death of a mother, witnessing of frequent violence and sexual abuse.

Clinicians practicing in rural areas therefore need a higher index of suspicion for this disorder when managing adolescents. General physicians and primary health workers also need training to recognize this disorder, as they are more likely to see patients in the early stages before co-morbid conditions develop. The factors identified to be significantly associated with adolescent depression may also be helpful when designing and implementing preventive or in intervention programs.

\section{Limitations}

1) This study was cross sectional in design; a longitudinal study would have provided more information as to cause and effect of depression in adolescent subjects. However, time constraints would not allow such a study design.

2) This study did not assess the severity nor co-morbidity associated with depression.

3) The instruments used for the screening and diagnosis of depression in this study were not translated to the local language of the respondents. However, efforts were made to ensure that the questions were properly understood by the participants.

4) Correlates such as sexual abuse, physical abuse and violence were self reported by the study participants and it is possible there might have been some recall bias.

\section{References}

[1] World Health Organisation (1992) Tenth Revision of the International Classification of Diseases and Related Health Problems (ICD - 10).

[2] Peterson, A.C., Compass, B.E., Brooks-Gunn, J., Stemmlier, M., Ey, S. and Grant, K.E. (1993) Depression in Adolescence. American Journal of Psychology, 48, 155-168. https://doi.org/10.1037/0003-066X.48.2.155

[3] World Health Organization (WHO) Guidelines (2008) Ten Facts on Adolescent Health.

[4] Saluja, G., Iachan, R., Scheidt, P., Overpeck, M., Sun, W. and Giedd, J. (2004) Prevalence and Risk Factors for Depressive Symptoms among Young Adolescents. Archive of Paediatric Adolescent Medicine, 158, 760-765. https://doi.org/10.1001/archpedi.158.8.760

[5] Kahn, J. (1995) Adolescent Depression: An Overview.

[6] Mathet, F., Martin-Guehl, C., Maurice Tison, S. and Bouvard, M.P. (2003) Prevalence of Depressive Disorders in Children and Adolescents Attending Primary Care. A survey with the Aquitaine Sentinelle Network. Encephale, 29, 391-400.

[7] Khasakhala, L.I., Ndetei, D.M., Mutiso, V., et al. (2012) The Prevalence of Depressive Symptoms among Adolescents in Nairobi Public Secondary Schools; Association with Perceived Maladaptive Parental Behaviour. African Journal of Psychiatry, 
15, 106-113. https://doi.org/10.4314/ajpsy.v15i2.14

[8] Omigbodun, O.O., Esan, O., Bakare, K., et al. (2004) Depression and Suicidal Symptoms among Adolescents in Rural South Western Nigeria. 16th World Congress of the International Association for Child and Adolescent Psychiatry and Allied Professions (IACAPAP), Berlin, 22-26.

[9] Oyedeji, G.A. (1995) Socioeconomic and Cultural Background of Hospitalized Children and Adolescents in Ilesha. Nigeria Journal Paediatrics, 12, 111-117.

[10] Adewuya, A.O., Ola, B.A. and Afolabi, O.O. (2006) Validity of the PHQ as a Screening Tool for Depression among Nigerian Students. Journal of Affective Disorders, 96, 89-93. https://doi.org/10.1016/j.jad.2006.05.021

[11] Gureje, O., Omigbodun, O., Gater, R., et al. (1994) Psychiatric Disorders in a Paediatric Primary Care Clinic. British Journal of Psychiatry, 165, 527-530. https://doi.org/10.1192/bjp.165.4.527

[12] Khalil, A.H., Rabie, M.A., Abd-El-Azz, M.F., et al. (2010) Clinical Characteristics of Depression among Adolescent Females. A Cross Sectional Study. Journal of Child and Adolescent Psychiatry, 4, 26. https://doi.org/10.1186/1753-2000-4-26

[13] Omigbodun, O., Bakare, K. and Yusuf, B. (2008) Traumatic Events and Depressive Symptoms among Youths in South West, Nigeria: A Qualitative Analysis. International Journal of Adolescent Medical Health, 20, 243-253.

[14] Johnson, J.G., Harris, E.S., Spitzer, R.L. and Williams, B.W. (2002) The Patient Health Questionnaire for Adolescents. Validation of an Instrument for Assessment of Mental Disorders among Adolescent Primary Care Patient. Journal of Adolescent Health, 30, 196-204. https://doi.org/10.1016/S1054-139X(01)00333-0

[15] Ganguly, S., Samanta, M., Roy, P., Chaterjee, S., et al. (2013) PHQ-9 as an Effective Tool for Screening of Depression among Indian Adolescents. Journal of Adolescent Health, 52, 546-551.

[16] Richardson, L.P., McCauley, E., Grossman, D.C., McCarty, C.A., et al. (2010) Evaluation of the Patient Health Questionnaire-9 Item for Detecting Major Depression among Adolescents. Paediatrics, 126, 1117-1123.

https://doi.org/10.1542/peds.2010-0852

[17] Fatiregun, A.A. and Kumapayi, T.E. (2014) Prevalence and Correlates of Depressive Symptoms among School Adolescents in a Rural District in South West, Nigeria. Journal of Adolescence, 37, 197-203. https://doi.org/10.1016/j.adolescence.2013.12.003

[18] Endicott, J. and Spitzer, R.L. (1978) A Diagnostic Interview: The Schedule for Affective Disorder and Schizophrenia. Archive of General Psychiatry, 35, 873-844. https://doi.org/10.1001/archpsyc.1978.01770310043002

[19] Nagendra, K., Sangay, D., Gouli, C. and Kalappanavar, N.K. (2012) Prevalence and Association of Depression and Suicidal Tendency among Adolescent Students in Davangere, India. International Journal of Biomedical and Advance Research, 3, 714-918.

[20] Said, B. and Hasan, K. (2009) Prevalence of Depressive Symptoms in Turkish Adolescents. European Journal of General Medicine, 6, 204-212. https://doi.org/10.29333/ejgm/82671

[21] Bahls, S. (2002) Epidemiology of Depressive Symptoms in Adolescents of a Public School in Curitiba, Brazil. Brazilian Journal of Psychiatry, 24, 63-67. https://doi.org/10.1590/S1516-44462002000200005

[22] Frank, E., Carpenter, L.L. and Kupfer, D.J. (1988) Sex Differences in Recurrent Depression: Are There Any That Are Significant? The American Journal of Psychiatry, 
145, 41-45. https://doi.org/10.1176/ajp.145.1.41

[23] Kessler, R.C., McGonagle, K.A., Swartz, M., et al. (1993) Sex and Depression in the National Comorbidity Survey I: Lifetime Prevalence, Chronicity and Recurrence. Journal of Affective Disorders, 29, 85-96. https://doi.org/10.1016/0165-0327(93)90026-G

[24] Abdel-Azis, M.F., Abdel-Hady, N., Elimissiry, S.M., El-Rasheed, A. and Sabry, W. (2013) Prevalence of Depression in a Sample of Egyptian Secondary School Female Students. Egyptian Journal of Psychiatry, 1-12.

[25] Polit, D.F. (1982) Family Size and Child Development. Draper Fund Report, 12, 19-22.

[26] Lin, H.-C., Tang, T.-C., Yen, J.-Y., Ko, C.-H., Huang, C.-F., Lius, S.-C., et al. (2008) Depression and Its Association with Self Esteem, Family Peer and School Factors in a Population of 9586 Adolescents in Southern Taiwan. Psychiatry and Clinical Neurosciences, 62, 412-420. https://doi.org/10.1111/j.1440-1819.2008.01820.x

[27] Simons, R., Gordon, L., Conger, R. and Loren, X. (1999) Explaining the High Incidence of Problems among Children of Divorced Compared with Those in Two Parents Families. Journal of Marriage and Family, 61, 1020-1033.

https://doi.org/10.2307/354021

[28] Adewuya, A.O. and Ologun, V.A. (2006) Factors Associated with Depressive Symptoms in Nigeria Adolescents. Journal of Adolescent Health, 39, 105-110. https://doi.org/10.1016/j.jadohealth.2005.08.016

[29] Adams, D.B. (2009) Parental Death and Teenage Depression. American Journal of Psychiatry, 166, 786-794.

[30] Slavich, G.M., Monroe, S.M. and Gotlib, I.H. (2011) Early Parental Loss and Depression History: Associations with Recent Life Stress in Major Depressive Disorder. Journal of Psychiatric Research, 45, 1146-1152. https://doi.org/10.1016/j.jpsychires.2011.03.004

[31] JAMA and Archives Journals (2011) Grief Reactions Subside in Most Children and Teens Whose Parents Die Suddenly but May Persist or Increase in Some Cases. (Internet). ScienceDaily. 